OPEN ACCESS

Edited by:

Llewellyn Ellardus Van Zyl,

North-West University, South Africa

Reviewed by:

Piers Worth,

Buckinghamshire New University,

United Kingdom

Richard Appiah,

University of Ghana, Ghana

${ }^{*}$ Correspondence:

Rachel Colla

rachel.colla@unimelb.edu.au

Specialty section:

This article was submitted to

Positive Psychology,

a section of the journal

Frontiers in Psychology

Received: 04 November 2021

Accepted: 17 January 2022

Published: 23 February 2022

Citation:

Colla R, Williams P, Oades LG and

Camacho-Morles J (2022) "A New

Hope" for Positive Psychology:

A Dynamic Systems

Reconceptualization of Hope Theory.

Front. Psychol. 13:809053.

doi: 10.3389/fpsyg.2022.809053

\section{"A New Hope" for Positive Psychology: A Dynamic Systems Reconceptualization of Hope Theory}

\author{
Rachel Colla*, Paige Williams, Lindsay G. Oades and Jesus Camacho-Morles \\ Centre for Wellbeing Science, Melbourne Graduate School of Education, University of Melbourne, Parkville, VIC, Australia
}

In this review of the central tenets of hope theory, we examine the meta-theoretical, theoretical, and methodological foundations of the literature base. Our analysis moves from a broad examination of the research landscape in hope theory across disciplines, to a deeper investigation of the empirical literature in university students. This review highlights the significant impact of this body of research in advancing our understanding of aspects of thriving characterized by hope. However, we also evidence several limitations that may impede the advancement of the next wave of growth in this field. To address these limitations, we argue for an interdisciplinary approach to expanding the meta-theoretical, theoretical, and methodological horizons, enabling a more dynamic systems approach to the study of hope. Drawing on the intersection of positive psychology with systems thinking, we describe a methodological approach that enables a deeper examination of the processes and interactions through which hope emerges, using an analysis of the lived experience of young people. It is proposed that this research agenda will bring to life an alternate story about the resourcefulness of our youth through their own voice, enabling us to leverage this in the design of more effective strategies to facilitate hope in the future. This research agenda provides a roadmap that will provide alternative methodologies that address the current limitations in the field of hope research and, importantly, can provide fuel to spur on the acceleration of the next wave of research and practice in the field of positive psychology more broadly.

\section{Keywords: systems dynamics, interdisciplinary, hope theory, methodology, meta-theoretical}

\section{INTRODUCTION}

"A long time ago in a galaxy far, far away".... With this phrase, George Lucas launched what was to become one of the most successful cinematic epic sagas in recent history. In a thought-provoking choice, Lucas began the series in the middle of a story, launching with the fourth episode, Star Wars: A New Hope, for technical and storytelling reasons. The story launches straight into the action while hinting at untold history. In a parallel universe, Rick Snyder launched a theory of hope that has helped drive the significant growth and impact of the field of positive psychology, but there is a sense that there was more to this story. As hope theory enters its third decade of research, the first trilogy if you like, many storylines have been explored, with the opportunity now for some deeper character development. In this critically appraised topic (CAT) review, we explore the roots of the hope theory story by examining the meta-theoretical, theoretical, and methodological assumptions 
that underpin the research. As the story develops, we argue that drawing on multi-disciplinary approaches, such as complex dynamic systems, will help tell some of the "untold history" and thus deepen understanding of the interactions that facilitate aspects of thriving characterized by hope.

Early positive psychology researchers set the tone for significant growth and development of the field, influenced by the desire to provide a systematic and rigorous approach to the scientific study of what enables thriving, or optimal development, across various life domains. As a result, much of the metatheoretical and methodological development of research and practice has been grounded in a dualist positivist epistemology and realist ontological view of the world as "knowable" (Gergen, 1990). This paradigm sees reality as objectively observable, fixed, and generalizable; as such, it transcends context (Ward et al., 2015). However, the unintended consequence of this has led to one of the most persistent criticisms of the field, namely, that there is a dominant focus on the individual that lacks an appreciation of contextual and dynamic influences on thriving (Kern et al., 2020).

This limitation is epitomized in Snyder et al.'s (1991) hope theory. While Snyder's conceptualization of hope articulated an iterative and dynamic process between agency (goal-directed energy) and pathway thinking (planning to meet goals), the methods through which it was operationalized and measured produced a more linear and acontextual construct in the empirical literature. We argue that the dynamic tenets of hope theory that have been left on the "editing floor" with this technical limitation provide valuable insights into the mechanisms that enable the core capabilities to develop. Moreover, the theory is framed in an individualistic cultural perspective and thus may lack applicability to more collectivist cultures. For example, in a conjoint perspective of agency, goals, and actions are defined interpersonally rather than individually and often reflect individuals' interdependence and position within social situations (Bernardo, 2010). This is not represented in the current liberal individualist conceptualization of hope theory.

This manuscript reviews the evolution of research on Snyder's hope theory and the substantial body of evidence linking hope with adaptive functioning. The review reveals several unanswered questions around the mechanisms that facilitate these links that have not been resolved through current methodological approaches. With a meta-analysis demonstrating only small effect sizes, particularly across different contexts (Weis and Speridakos, 2011), the effectiveness of the translation of this body of research to practice can also be questioned. These limitations suggest the need for a deepened understanding of how hope emerges; one that recognizes and addresses the inherent complexities in the emergence of hope and is grounded in the lived experience of different sociocultural contexts.

Scholars have recently recognized the need to expand positive psychology toward more complex understandings of the factors and contexts influencing wellbeing. For example, Kern et al.'s (2020) proposal of systems informed positive psychology (SIPP) and Lomas et al.'s (2020) illumination of the dynamics that can broaden the field toward complexity. In this manuscript, we take up this call for a broadened perspective to one area of positive psychology-hope theory-and in doing so, provide "a new hope" for how these aspirations can be translated into research practice.

\section{Our Research Agenda}

The research agenda we propose aims to address some of these limitations by taking an integrated multi-disciplinary perspective, expanding the current meta-theoretical, theoretical, and methodological approaches that have underpinned the hope research to date. The model we propose expands Snyder's conceptualization to incorporate an additional interpersonal factor (WePower) and intrapersonal factor (WhyPower), in addition to existing elements of hope theory, motivation to succeed (WillPower), and planning to meet goals (WayPower). The interplay between these factors is a crucial focus of this research agenda, enabling a more dynamic systems model of hope to be developed. In the expanded model we propose, hope is conceptualized as an emergent property that cannot be fully understood by breaking the construct down into its constituent parts; instead, it is an energy system derived from the dynamic interplay between the parts.

A systems approach argues that more profound knowledge and meaningful understanding come from constructing whole pictures and examining the interrelatedness of factors rather than examining factors in isolation (Flood, 2010). Therefore, drawing from the intersection of positive psychology with complex systems dynamics, we describe a methodological approach that enables a deeper examination of the processes and interactions that facilitate hope to emerge through an analysis of the lived experience of young people. This mixed-methods approach addresses the call for more qualitative research in exploring optimal functioning, proposed by Hefferon et al. (2017), without compromising the systematic rigor aspirations of the founding scholars of positive psychology.

It is proposed that this research agenda will bring to life an as yet untold story about the resourcefulness of our youth through their own voice, enabling us to leverage this in the design of more effective strategies to facilitate hope in the future. Our purpose is to offer a roadmap that will provide alternative methodologies to address the current limitations in hope research and offer insights that can enhance research and practice in positive psychology more broadly.

\section{HOPE RISING: AN ANALYSIS OF THE DEVELOPMENT OF HOPE THEORY}

Hope has captured the attention of philosophers, poets, artists, and scholars throughout the ages. In the late 20th Century, numerous social scientists turned their attention to operationalizing hope, with more than 26 theories or definitions generated (Lopez et al., 2003). There is consistency in the core themes underpinning these different theories, namely, that hope is a human strength that enables individuals to draw on resources in their environment to support pathways toward healthy development and achievement. The vast majority of these theories operationally defined hope as a unidimensional 
construct grounded in a positive expectation that goals can be met (see Callina et al., 2018 for a review of the history of conceptualizations of hope). However, Snyder et al.'s (1991) twofactor model of hope has dominated the psychological literature over the last 30 years and is one of the key theories underpinning the development of positive psychology.

Snyder et al.'s (1991) theory defines hope as a dynamic motivational experience that is interactively derived from two distinct types of cognitive tools in the context of goal achievement-namely, pathways and agency thinking. His theory proposes that hope results from an individuals' perceived ability to develop numerous and flexible pathways toward their goals, allowing them to identify barriers and strategies to overcome these as they move toward goal achievement (WayPower). It is further fueled by the individuals' sense of agency in their goal pursuit, defined as goal-directed energy or determination to succeed (WillPower) (Snyder et al., 1991). These two factors are theorized to be positively related yet distinct (Snyder, 1989). That is, one can have a strong sense of agency without necessarily demonstrating successful pathways planning toward their goals. However, the additive, reciprocal relationship between the two factors results in a cumulative positive experience of hope that provides the dynamic motivation to act-a key differentiator of hope theory from other related constructs such as optimism and self-efficacy (Snyder, 2002). The theory has expanded from its original proposition of hope as a trait, or disposition consistent across time and situations, to now include evidence of hope as a state or momentary experience (Snyder et al., 1996), as well as being specific to certain life domains (Robinson and Rose, 2010).

The last 30 years have seen significant growth in the research on hope theory, demonstrating the applicability and relevance of the theory that has built its own "epic story." A comprehensive search of the literature that examined the central tenets and correlates of hope theory was conducted across multiple databases, including Ovid (PsycInfo), Web of Science, PubMed, EbscoHost (ERIC and ERC), and Scopus. To explore evidence of the growth and reach of this theory across disciplines and applications, we mapped this literature over time (see Figure 1) and across disciplines (see Figure 2). It should be noted that given the focus on the methodological and meta-theoretical foundations of this manuscript, the review was limited to peer-reviewed journal articles and doctoral theses. It does not represent the significant number of chapters and books that have also been published, nor the articles that have utilized hope theory as a theoretical argument to explain their findings, both of which further evidence the significant impact and application of this theory.

Apart from a slight decline in publications over the 2020/2021 years, which could be explained by the significant impact of the global pandemic on research, there has been a consistent growth pattern in the development of the evidence base for hope theory. Snyder's theory has also attracted researchers across a broad range of disciplines and applications, which has seen an expansion beyond psychology to a range of applications such as education, sport, psychotherapy, organizational science, and medicine (see Figure 2).
Placing the development of this theory in a sociohistorical context is essential in elucidating some of the dominant ways of knowing or epistemology that underpin the evidence base. Psychological researchers, particularly in the context of building an evidence base to argue for the merits of a new field such as positive psychology, have been grounded in a specific sociohistorical narrative of what constitutes new knowledge (Shotter, 1993). In this context, it is unsurprising that positivist approaches have dominated the assumptions that underpin hope theory development and subsequent research methodologies. They arose in the sociohistorical context of Seligman's call to arms for a "rigorous" approach to building knowledge of what makes life worth living, driven by the presiding narrative in psychological research at the time that "rigorous" equated to knowledge derived in quantitative terms.

Hope theory was also developed within the context of the rise of motivational literature and cognitive revolution occurring during this period. Snyder (2002) himself comments on the significant influence of Karl Menninger. The latter actively encouraged the prioritization of cognitive processes, with emotions being conceptualized as a secondary affective response to cognitive appraisals of agency and pathways planning. What resulted was a theory of hope as a way of thinking, with emotional responses proposed to be a consequence of the experience of hope rather than a fundamental contributor to driving goal-related performance (Snyder et al., 1999).

The language that Snyder used to communicate the theoretical tenets of this theory indicates a dynamic process, such that adaptive behaviors and characteristics are both the cause and consequence of hope (Snyder, 2002). However, when driven by a process of knowledge acquisition that necessitates the development of measurement scales through factor analysis, the consequence was an operationalization of hope as individual factors rather than an interconnected construct. The resulting literature thus predominantly focuses on the contributory roles of these two factors-both independently and as a combined factor-than on the dynamics between them. Further, the contributions of emotional responses or other types of causal attributions that enable hope to emerge have also been overlooked. While Snyder incorporates the feedback and feedforward loops of emotions and cognitions in his theoretical model, this is not operationalized in his measure of hope. The more reductionistic nature of the methodologies to date also makes it harder to interpret the potential multidirectionality of these relationships and the mechanisms through which hope emerges.

\section{The Landscape of Hope in University Students}

The shortcomings and limitations discussed above are well evidenced in a review of the literature in the university student population. A review of over 60 empirical studies on young people in higher education has highlighted the dominance of positivist epistemological approaches underpinning much of the research. There is no doubt that these methodologies have made a significant contribution to the knowledge that 

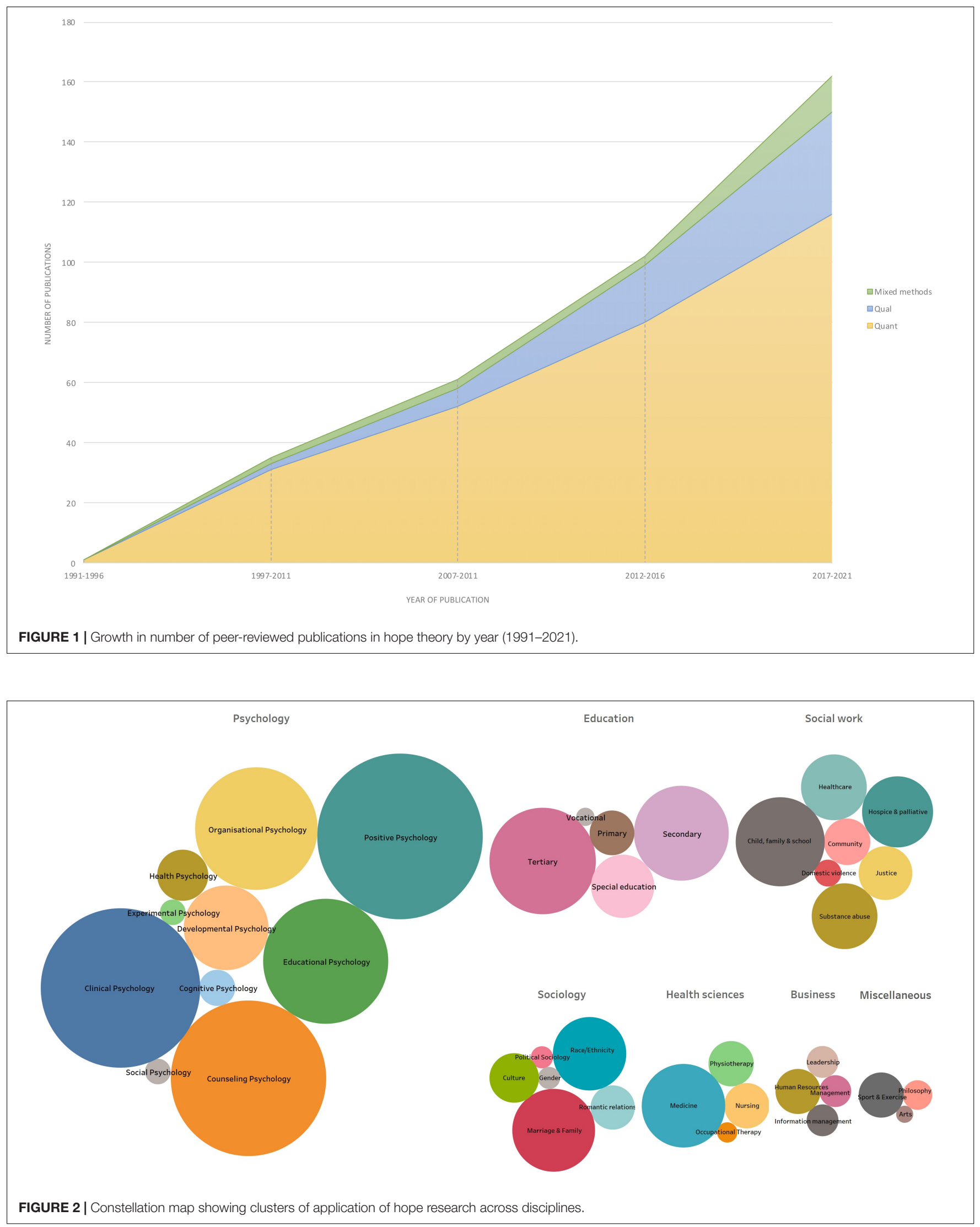
young people with a high sense of hope exhibit adaptive psychological and school-related functioning (see Table 1). For example, this body of evidence has demonstrated that hope is related to numerous factors relevant to the success of young people during their tertiary studies. Hope has direct associations with academic achievement (Snyder et al., 2002; Collins et al., 2009; Davidson et al., 2012; Feldman and Kubota, 2015; Feldman et al., 2015; Griggs and Crawford, 2017), as well as a range of characteristics related to academic success, including perceived control and exam performance (Crane, 2014), coping strategies for study (Onwuegbuzie and Snyder, 2000), persistence (Muwonge et al., 2017), psychological grit (Cavazos Vela et al., 2018), self-efficacy (Davidson et al., 2012; Macaskill and Denovan, 2013), higher engagement and motivation (Dixson, 2019), autonomous learning, social self-efficacy and self-esteem (Macaskill and Denovan, 2013).

The literature has evidenced strong links between hope and measures of psychological and emotional wellbeing in higher education students (Chang and Banks, 2007; Wandeler and Bundick, 2011; Macaskill and Denovan, 2013; Griggs and Crawford, 2017; Bernardo et al., 2018; Chang et al., 2019). Therefore, hope is an influential protective factor for mental health and wellbeing, making it particularly valid, valuable, and relevant to the challenging transition periods both into and out of tertiary studies. The buffering and building effects hope provides are relevant for building capability to thrive and managing significant challenges. For example, hope mediates psychological adjustment, even in the face of trauma and adversity (Liu et al., 2017), and acts as a protective factor for suicide risk (Davidson and Wingate, 2011; Lucas et al., 2020).

It is also pertinent that hope may be particularly important for those in lower socioeconomic situations, as it is neither significantly related to intelligence (Snyder et al., 2002) nor income (Gallup, 2009). In general, high hope individuals are energetic and intrinsically motivated; able to set clear goals based on their own standards rather than others, and perceive obstacles as challenges that they can overcome with contingency planning (Chang, 1998; Snyder, 2002; Lopez, 2010; Gallagher et al., 2017). Increased hope can act as an enabling factor for those in lower socioeconomic situations, broadening perspectives on the possibilities available and providing motivation to tap into resources to support goal achievement (Dixson et al., 2017).

Hope may also be considered a robust social leveler. Hope can mediate the relationship between socioeconomic status and academic achievement (Dixson et al., 2017). It is predictive of adaptive functioning in an educational setting, even when controlling for intelligence (Snyder et al., 1997), prior academic history (Gallagher et al., 2017), and self-esteem (Snyder et al., 2002). There is also evidence that hope is particularly important in predicting student resilience, especially in response to uncertainty (Goodman et al., 2017). Indeed, as studies begin to emerge from the recent global pandemic, we can see the role that hope played in navigating some of the extraordinary challenges facing students. For example, a recent study of nearly 6,000 Chinese students in the first wave of lockdowns indicated that hope moderated the relationship between family functioning, loneliness, and mental health (Pan et al., 2021). This research evidences that hope is a critical construct to explore further as we prepare our youth for a volatile, uncertain, complex, and ambiguous (VUCA) world. However, it does not tell us the story of the mechanisms through which these positive associations are achieved. In essence, returning to our Star Wars analogy, this got us straight into the action while acknowledging an untold history still to explore.

\section{The Missing Pieces of the Story: Identifying Core Gaps in the Research}

In recent years, this missing storyline has begun to be addressed in the hope literature. Several studies utilized path analysis to examine the mediation or moderation role that agency and pathways thinking play in the links to adaptive outcomes. For example, Luo et al. (2019) tested a comprehensive model of the role different aspects of hopeful thinking play in linking to various factors that support learning outcomes, such as teacher and peer support, self-esteem, and belonging. However, the extant literature predominantly focused on demonstrating the utility of hope, missing a depth of examination on some of the core tenets of the theory. This includes its antecedents and the pathways through which hope develops. Cheavens et al. (2019) cite this as their core motivation in a recent study that validated that dispositional hope was related to pathways-generating behaviors and goal setting.

A deeper analysis of the hope literature in university students shows that researchers have not yet thoroughly examined whether hopeful cognitions lead to positive affect or indeed whether the emotional experience is a mechanism that develops agency or pathways thinking. Snyder's theory is that these create an iterative and reciprocal feedback system, but how this has been operationalized and evaluated in the current literature does not build up a "whole picture" of this dynamic process. The two-factor measurement of hope and subsequent analyses of its antecedents, correlates, and outcomes precludes an analysis of the dynamic interaction between these factors to facilitate adaptive relationships, including the mechanisms through which the theoretical reciprocal feedback system functions. Hope also forms a nomological network with other expectancy variables such as self-efficacy, locus of control, and optimism that have been shown to lead to adaptive outcomes (Tennen et al., 2002). While evidence has demonstrated that these variables are distinct but related constructs (Magaletta and Oliver, 1999), much of the research has used path analyses to explain their moderation or mediation impact on adaptive outcomes. However, we believe that this "component" approach to the operationalization of hope does not fully represent the rich and complex interactions that may account for these relationships. With this model of measurement we cannot account for the ways in which pathways thinking and agency thinking may interact in different circumstances, limiting our knowledge and resulting practice to enhance opportunities for hope to emerge.

Despite claims that hope is malleable, there is also limited experimental research in this population that examines how hope develops or whether interventions based on the premises of hope theory effectively increase hope. The small number of 
TABLE 1 | Summation of research testing hope theory propositions, correlates, and outcomes in young people in higher education.

\begin{tabular}{|c|c|c|c|c|c|c|}
\hline Author(s), year & Approach & Methods/Design & Antecedents & $\begin{array}{l}\text { Correlates and } \\
\text { outcomes }\end{array}$ & Mediators/Moderators & Location \\
\hline & & & & $\begin{array}{l}\text { Academic achievement } \\
\text { and/or graduation success }\end{array}$ & & \\
\hline Snyder et al., 2002 & Deductive & $\begin{array}{l}\text { Regression } \\
\text { (Iongitudinal) }\end{array}$ & & GPA and Graduation status & & United States \\
\hline $\begin{array}{l}\text { Savage and Smith, } \\
2007\end{array}$ & Deductive & Regression & & Degree attainment & & United States \\
\hline $\begin{array}{l}\text { Papantoniou et al., } \\
2010\end{array}$ & Deductive & Path analysis & & Grades & Learning strategies & Greece \\
\hline $\begin{array}{l}\text { Davidson et al., } \\
2012\end{array}$ & Deductive & Quasi-experimental & & Grades* & & Israel \\
\hline $\begin{array}{l}\text { Feldman et al., } \\
2015\end{array}$ & Deductive & Quasi-experimental & & $\mathrm{GPA}^{*}$ & & Israel \\
\hline $\begin{array}{l}\text { Griggs and } \\
\text { Crawford, } 2017\end{array}$ & & & & $\begin{array}{l}\text { Characteristics related to } \\
\text { study success }\end{array}$ & & \\
\hline $\begin{array}{l}\text { Onwuegbuzie and } \\
\text { Snyder, } 2000\end{array}$ & Deductive & Correlational & & Coping strategies for study & & United States \\
\hline $\begin{array}{l}\text { Davidson et al., } \\
2012\end{array}$ & Deductive & Correlational & & $\begin{array}{l}\text { Sense of coherence, } \\
\text { self-efficacy* }\end{array}$ & & Israel \\
\hline $\begin{array}{l}\text { Macaskill and } \\
\text { Denovan, } 2013\end{array}$ & Deductive & Experimental & & $\begin{array}{l}\text { Autonomous learning, } \\
\text { course self-efficacy (agency } \\
\text { only) } \\
\text { Social self-efficacy } \\
\text { Self-esteem }\end{array}$ & & United Kingdom \\
\hline $\begin{array}{l}\text { Muwonge et al., } \\
2017\end{array}$ & Inductive & Path analysis & & Persistence $^{\star \star}$ & & Uganda \\
\hline Luo et al., 2019 & & & & Goal progress/attainment & & \\
\hline $\begin{array}{l}\text { Feldman et al., } \\
2009\end{array}$ & Deductive & $\begin{array}{l}\text { Path analysis } \\
\text { (longitudinal) }\end{array}$ & & Goal attainment & Goal specific hope $e^{\star \star}$ & United States \\
\hline $\begin{array}{l}\text { Feldman and } \\
\text { Dreher, } 2012\end{array}$ & Deductive & Experimental & & Goal progress & & United States \\
\hline Crane, 2014 & Deductive & Regression & & $\begin{array}{l}\text { Exam performance, } \\
\text { approach motivations, } \\
\text { perceived control }\end{array}$ & & Australia \\
\hline \multirow[t]{2}{*}{$\begin{array}{l}\text { Cheavens et al., } \\
2019\end{array}$} & Deductive & Regression & & $\begin{array}{l}\text { Important, prosocial, } \\
\text { long-term, and challenging } \\
\text { goals }\end{array}$ & & United States \\
\hline & & & & Wellbeing and adjustment & & \\
\hline $\begin{array}{l}\text { Chang and } \\
\text { DeSimone, } 2001\end{array}$ & Deductive & Path analysis & & $\begin{array}{l}\text { Psychological adjustment } \\
\text { (direct and indirect) }\end{array}$ & Appraisals and coping & United States \\
\hline $\begin{array}{l}\text { Denovan and } \\
\text { Macaskill, } 2013\end{array}$ & Inductive & $\begin{array}{l}\text { Interpretive/ } \\
\text { phenomenological }\end{array}$ & & $\begin{array}{l}\text { Stress and coping in } \\
\text { transition to university }\end{array}$ & & \\
\hline Liu et al., 2017 & Inductive & Regression & & $\begin{array}{l}\text { Adjustment to collective } \\
\text { trauma }\end{array}$ & & United States \\
\hline \multirow{2}{*}{$\begin{array}{l}\text { Griggs and } \\
\text { Crawford, } 2017\end{array}$} & Deductive & Path analysis & & Emotional wellbeing & Core self-evaluations & United States \\
\hline & & & & $\begin{array}{l}\text { Career choice/vocational } \\
\text { calling }\end{array}$ & & \\
\hline
\end{tabular}


TABLE 1 | (Continued)

\begin{tabular}{|c|c|c|c|c|c|c|}
\hline Author(s), year & Approach & Methods/Design & Antecedents & $\begin{array}{l}\text { Correlates and } \\
\text { outcomes }\end{array}$ & Mediators/Moderators & Location \\
\hline Phillips, 2011 & Deductive & Path analysis & & $\begin{array}{l}\text { Vocational calling (for } \\
\text { women but not men) }\end{array}$ & & United States \\
\hline $\begin{array}{l}\text { Feldman and } \\
\text { Dreher, } 2012\end{array}$ & Deductive & Experimental & & $\begin{array}{l}\text { Vocational calling and life } \\
\text { purpose }\end{array}$ & & United States \\
\hline Eren, 2015 & Inductive & Path analysis & & $\begin{array}{l}\text { Satisfaction with career } \\
\text { choice and sense of } \\
\text { responsibility }\end{array}$ & & Turkey \\
\hline $\begin{array}{l}\text { Buyukgoze-Kavas, } \\
2016\end{array}$ & Deductive & Regression & & $\begin{array}{l}\text { Career adaptability and } \\
\text { resilience } \\
\text { Predictors of hope }\end{array}$ & & Turkey \\
\hline $\begin{array}{l}\text { Ahmet and Umran, } \\
2014\end{array}$ & Deductive & Regression & Authenticity & & & Turkey \\
\hline $\begin{array}{l}\text { Soria and } \\
\text { Stubblefield, } 2015\end{array}$ & Deductive & Regression & $\begin{array}{l}\text { Strengths- } \\
\text { awareness and } \\
\text { self-efficacy }\end{array}$ & & & \\
\hline Cole et al., 2019 & Deductive & Path analysis & $\begin{array}{l}\text { Gender role } \\
\text { conflict } \\
\text { (negative } \\
\text { relationship) }\end{array}$ & $\begin{array}{l}\text { Gender } \\
\text { socialization-conformity to } \\
\text { masculine norms (agency } \\
\text { only) }\end{array}$ & & United States \\
\hline Luo et al., 2019 & Deductive & Path analysis & $\begin{array}{l}\text { Social support, } \\
\text { belonging, } \\
\text { self-esteem }\end{array}$ & & & Taiwan \\
\hline \multirow[t]{2}{*}{ Chang et al., 2019} & Deductive & Path analysis & Positive affect & Life satisfaction & $\begin{array}{l}\text { Hope agency but not } \\
\text { pathways }\end{array}$ & China \\
\hline & & & & Individual differences & & \\
\hline $\begin{array}{l}\text { Chang and Banks, } \\
2007\end{array}$ & Inductive & Regression & $\begin{array}{l}\text { Life } \\
\text { satisfaction, } \\
\text { problem- } \\
\text { solving style, } \\
\text { positive affect, } \\
\text { problem } \\
\text { orientation }\end{array}$ & $\begin{array}{l}\text { Variations in levels of } \\
\text { agency and pathways } \\
\text { thinking between Latino, } \\
\text { European, Asian, and } \\
\text { African Americans }\end{array}$ & & \\
\hline
\end{tabular}

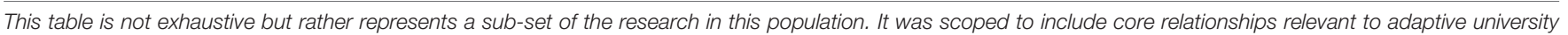
experience for students.

Unless otherwise stated, the relationships in the table are related to trait measures of hope.

${ }^{*}$ Related to state measure of hope.

${ }^{*}$ Related to domain measures of hope.

experimental studies with young adults have mainly focused on how short hope interventions affect academic performance outcomes (Macaskill and Denovan, 2013; Feldman et al., 2015; Harris, 2015), with some evidence of interventions increasing levels of hope (Davidson et al., 2012; Feldman and Dreher, 2012). Furthermore, a meta-analysis of hope interventions in both community and clinical settings reveal only small effect sizes and inconsistent results depending on the context in which they are delivered (Weis and Speridakos, 2011). Integrated interventions that include other practices based on adaptive constructs such as gratitude or psychological capital (a multi-component construct that includes hope, self-efficacy, resilience, and optimism), have shown increases in hope (Bauman, 2015; Baumsteiger et al., 2019), which further indicates the need to understand the different mechanisms that facilitate the development of hope. Added to this is a lack of inductive or exploratory approaches in research designs that enable a more nuanced picture of hope emerging to be examined. In fact, of all the studies reviewed, only a small handful utilized a mixed-methods or qualitative design, and these were predominantly doctoral theses.

Our review has highlighted that more research is needed to develop a deeper understanding of the factors and interactions that enable hope to emerge in young people. However, we argue that this needs to extend beyond the linear models prevalent in existing meta-theoretical assumptions and methodologies. This is evident from examining the gaps in the evidence base we have discussed thus far and the dearth of hope in our young people. For example, the current landscape reveals that less than half (46\%) of Australian and New Zealand school students could be classified as hopeful (Gallup, 2021), indicating that a significant portion of our youth lack abundant ideas and energy for the future. Unfortunately, this trend is replicated in other OECD countries (Gallup, 2018) and highlights a "wicked" problem that is complex, arises from non-linear dynamics, and may have multiple possible causes (Peters, 2017). To address such complexities calls for an expansion in approaches 
underpinning theoretical and methodological designs, allowing us to examine the complex interactions and factors that impact hope development in young people.

\section{ADOPTING A SYSTEMS VIEW OF HOPE}

Hope theory, as a cognitive model centered on the individual, is grounded in the liberal individualist sociohistorical context in which it was conceived; however, the emergence of postpositivist and post-modern epistemologies signify growing awareness of the challenges inherent in defining truth in a way that transcends context and abstracts individuals from their environment (Gergen, 1990; Ward et al., 2015; Goldman and O'Connor, 2021). The development of social epistemologies such as social constructionism, that recognize the effects of social interactions and social systems, helps redress this imbalance (Goldman and O'Connor, 2021), and recent developments in positive psychology have acknowledged this with a call toward interdisciplinary perspectives that better address the complexity of human behavior (Kern et al., 2020; Lomas et al., 2020). In an eloquent analogy, Lomas et al. (2020) acknowledge the opportunity in the power and energy generated by the last three decades of research to now propel us forward with the emergence of a new wave in positive psychology; one that moves beyond the individual to embracing complexity. It is with this philosophical intent that we argue that the intersection of systems science and more recent developments in wellbeing science can help address some of the limitations inherent in the current meta-theoretical propositions of hope theory and may inform and energize the next wave of research in this area.

Optimal functioning is recognized to be the outcome of complex and interactive processes, predispositions, and experiences (Roffey, 2015). It includes multiple contributory factors-personal and environmental (Keyes, 2006) - that occur in a nested ecological system. This dynamic ecological system encompasses the individual and many other layers of influence that support and guide development (Bronfenbrenner, 1979). While this approach to understanding optimal functioning is well established in many fields (e.g., sociology, anthropology, biology), positive psychology has been criticized for ignoring the influence of the larger context in favor of its focus on the individual (Kern et al., 2020). However, recent advances have begun to address this limitation in different contexts, such as Lomas et al.'s (2015) proposal of the Layered Integrated Framework Example (LIFE) for applied positive psychology and Williams et al.'s (2016) Inside-Out-Outside-In (IO-OI) model of workplace happiness. However, this criticism is still relevant to Snyder's hope theory in its acontextual perspective of individual capacity.

Snyder et al. (1991) were quite clear in arguing that they had drawn a clear boundary around the individual, stating that their phenomenological conceptualization of hope could be considered egocentric in that it taps into how an individual perceives their ability to move toward goals, with external environmental influences being incorporated only through the lens of how the individual appraises them in relation to agency and pathways thinking. However, more recent advances in the development of hope theory among individuals from more collectivist social settings have expanded this to demonstrate the validity of an external and internal locus of hope. This additional dimension represents the influence of external agents (family, peers, spiritual) in the development of agency thinking (Bernardo, 2010; Du and King, 2013; Bernardo et al., 2018; Bernardo and Mendoza, 2020), providing evidence of the importance of broader system influences in the emergence of hope.

Furthermore, consideration of the dynamics within the human system also provides the opportunity to re-consider the interplay between emotions, cognitions, and somatic experiences that can influence the emergence of hope. One of the limitations of the meta-theoretical assumptions of Snyder's theory lies in a dualism view that sees the mind as separate from the body and operating independently from the physical world (Buetow, 2007). It is now well-established that mental and physical wellbeing are intimately and bi-directionally linked (Kemp and Quintana, 2013; Steptoe et al., 2015). The vagus nerve, for example, provides a vital structure that communicates between mind and body, providing the opportunity for both thoughts and behavior to influence aspects of wellbeing such as hope (Mead et al., 2021). The solid evidence base that has emerged in recent years regarding the interdependency between various internal factors and the experience of wellbeing calls for a deeper examination of the dynamic interplay of elements within the human system that can contribute to the emergence of hope.

We argue that re-imagining hope theory within a dynamic systems lens can help shine a light on the multiple contributory factors that facilitate the emergence of hope. We aim to expand the theoretical mechanisms that may facilitate Snyder's conceptualization of a dynamic motivation system that enables goal-directed behavior, reflecting developing knowledge of the interplay between the human system and within social systems. Our goal in expanding these theoretical tenets is to operationalize some of the dynamics left on the "editing floor" in the methodological translation of hope theory. For example, an extension of Snyder's two-factor model to a multicomponent dynamic systems model can be achieved by including a more contextual motivational component (WhyPower) at the intrapersonal level, and a social-contextual component (WePower) at the interpersonal level. In the following sections, we address these proposed theoretical expansions to hope theory, including the theoretical mechanisms through which these components could contribute to the emergence of hope.

\section{WhyPower (Intrapersonal Context)}

One of the guiding assumptions underpinning hope theory is that humans are goal-oriented (Snyder, 1989, 1995; Snyder et al., 1991). Snyder (2002) positions the importance of goals being of sufficient value to the individual to sustain conscious thought characterizing high hope; however, this criterion is not well represented in the operationalization of hope. One item on the hope trait scale measures an individual's capacity to "come up with many ways to get the things in life that are important to me" (Snyder et al., 1991). While this is clearly linked to pathways 
thinking around goals, it does not account for the goal-directed energy that valuable goals can ignite. Incorporating a measure of "sufficient value" in the individual's goals into a model of hope can provide vital insights into the mechanisms that may facilitate the emergence of hope and may be of particular importance for our research agenda's population, namely, emerging adulthood. We argue that this is best operationalized as a sense of meaning in our goals or WhyPower.

A search for meaning is a critical developmental task for adolescents (Bronk, 2013; Damon and Malin, 2020). While definitions of meaning vary widely, there is a consensus that meaning has two major components: comprehension and purpose (Steger, 2018a). Comprehension involves making sense and integrating experiences, while the purpose component involves actively pursuing long-term goals that reflect one's identity but also transcend narrow self-interests (Steger, 2018b). Studies have shown that both these components are positively associated with measures of adaptive functioning in young people (Abe, 2016). In their review of the links between hope and meaning, Feldman et al. (2018) note that the two constructs are "close cousins," both influencing and contributing to the other, with an average correlation of 0.67 . This relationship is also reflected in the links between Reker and Wong's (1988) conceptualization of meaning; "cognizance of order, coherence and purpose in one's existence, the pursuit and attainment of worthwhile goals, and an accompanying sense of fulfillment" (p. 221) and key elements of hope theory. Snyder (2002) himself suggested that hope and meaning are "companions," as he proposed that self-reflective hope thoughts lead to a sense of meaning.

While the strong links between meaning and hope have been demonstrated both longitudinally (e.g., Mascaro and Rosen, 2005) and cross-sectionally (e.g., Feldman and Snyder, 2005), the mechanisms through which this occurs have not yet been established. The comprehension component of meaning may provide valuable insights into how individuals develop a sense of agency and pathway thinking. For example, the process of making sense and integrating experiences may be a mechanism that facilitates a belief in one's capacity to move toward their goals effectively, as well as expediting divergent thinking that supports the development of pathways planning. In contrast, the purpose component may be a mechanism that facilitates goal-directed energy. Purpose also serves as a self-organizing principle that stimulates goals and manages behavior; it is imperative in guiding decisions about the use of finite resources and likely to lead to greater persistence (McKnight and Kashdan, 2009). Thus, a sense of WhyPower in ones' goals may lead to enhanced hope through providing energy and motivation with structure and direction (Mascaro and Rosen, 2005).

It is relevant to note that the search for meaning for many young people creates a sense of disconnect rather than leading them to a sense of purpose. One reason may be the context in which this occurs. For example, while many psychologists view purpose from a primarily individualistic perspective (e.g., Ryff, 1989; Damon et al., 2003), Keyes (2011), a sociologist, argues for a conceptualization that reflects that our lives are interwoven within a social construction. He suggests that when viewed through the lens of complete human development, purpose is not just about our own individual sense of direction, but also whether our lives are constructive and contribute to the collective. He terms this authentic purpose, defined as "a quality of being determined to do or achieve an end...that employs one's gifts, brings a deep sense of worth or value, and provides a significant contribution to the common good" (p. 286).

The role of social connectedness and relationships as a source of meaning has been well documented (e.g., Delle Fave et al., 2011), making it an important component of WhyPower. Furthermore, in a comparison of the differential effects of hope and optimism on various aspects of wellbeing, it was shown that hope was more important in contributing to the more purposeful components of wellbeing (Gallagher and Lopez, 2009). While the inclusion of WhyPower into a dynamic systems model of hope seeks to operationalize some of the cognitive and affective mechanisms at the individual level, it does not fully address the interplay between the individual and their interpersonal context, especially in terms of their access to resources that can facilitate hope.

\section{WePower (Interpersonal Context)}

Bernardo (2010) has argued that a limitation of Snyder's approach is that it does not consider whether the pathways or sense of agency are self-determined or may involve external agents. Expanding the horizon to examine the multi-directional links between individuals and their social context may be particularly relevant when discussing an adolescent population due to the strong developmental need for social engagement (Siegel, 2014). The developmental stage of late adolescence/emerging adulthood incorporates a second sensitive period of brain maturation that triggers important health behaviors, and studies have demonstrated the important protective factors that social patterns can provide in shaping adolescent wellbeing trajectories (Viner et al., 2012). Therefore, it is proposed that integrating an interpersonal perspective into an expanded model of hope theory may enhance our understanding and facilitate better outcomes for young people in higher education. We operationalize this as a sense of connectedness, or WePower, representing an individual's ability to tap into resources within their social system.

A fundamental meta-theoretical assumption of Snyder's hope theory is that hope both acts as a resource and facilitates the acquisition of other resources that support healthy development and achievement. Resources can be defined as internal or external entities that are either valued and relevant in their own right, or can be used to obtain valued ends (Hobfoll, 2002). While hope theory has focused on internal resources to date, we propose that external resources are equally important, as are the interrelationships between both forms. For example, how does social connectedness (external) impact the perception of access to resources (internal)? This may be particularly pertinent to students who have moved from being a "big fish in a small pond" in their secondary school context to being "one of many fish in a large pond" in their university context, impacting their perception of access to resources.

Social resources play an essential role in goal attainment and enhanced wellbeing (Hobfoll, 2002), and thus are a critical 
factor to incorporate in a dynamic systems perspective of hope. Kelly's (1966) seminal work on the relationships between social resources and wellbeing demonstrated the importance of people's perception of access to resources within their ecological environment. He described an ecological interplay in which resources are transferred between people and their social settings, demonstrating the importance of expanding the horizon beyond the individual to explore how their experience within an interpersonal context may facilitate the emergence of hope. For example, the sharing of experiences with others may be a crucial factor that builds social bonds, allows individuals to soothe the experience of negative emotions that arise from stressful events, and tap into the knowledge and experience of others to help create pathways toward goals (Smyth et al., 2012). Lee and Gallagher (2018) found that high hope individuals actively seek the support of others in working toward their goals but are also likely to support the goal pursuits of others that serve to strengthen social bonds. Their research highlights the dynamic interplay between the individual and their interpersonal context in developing hope, supporting the need for an expanded perspective.

It is important to note that while these two additional components of WhyPower and WePower have been articulated as separate elements, we argue that hope is best conceptualized as an emergent property that cannot be fully understood by breaking the construct down into its constituent parts. Instead, it is theorized as an energy system derived from the dynamic interplay between the parts. However, how to build up whole pictures of social phenomena poses a significant challenge that has created some controversy amongst systems thinkers as to what the best methodological approach is to achieve this (Flood, 2010).

\section{WHAT WE MEASURE (AND HOW) MATTERS}

One of the inherent limitations in methodological approaches that arise from a philosophical perspective that takes "an atomistic, ontological view of the world as comprising discrete, observable elements and events that interact in an observable, determined, and regular manner" (Collins, 2010, p. 38) is an oversimplification of dynamic processes. Logical positivist epistemology relies on reducing phenomena to the simplest elements and thus may limit the capacity to analyze the complexity and inherent "messiness" that characterizes human functioning, including reducing influences of the environment.

Given this landscape of knowledge development, it is unsurprising to see quantitative research designs dominating the literature in hope theory to date. Friedman (2003) argues that this seemingly religious devotion to one method and their underlying epistemologies are a flawed form of "methodoltry, the undue elevation of a method to a sacred artifact" (p. 817). While elements of this claim ring true, it is perhaps not a fair representation of the state of play in hope research to date. Indeed, these methods have built robust confidence in the impact of hopeful thinking and its role in adaptive functioning.
What is less clear from this literature, driven by deductive reasoning in research design, is the complex interactions that enable hope to emerge. Snyder's theory was seeded from his conversations with participants in his studies on excuse-making, but he has predominantly taken a top-down approach to theory development rather than a grounded theory approach. There is no doubt that his theoretical propositions draw on a solid evidence base, but this was not grounded in the lived experience of hope. We argue that there is more backstory (a prequel to the trilogy!) that would help articulate some missed nuances inherent in the experience of hope.

Some scholars have sought to remedy this limitation, but this has predominantly focused on more marginalized populations such as domestic violence support workers (Crain and Koehn, 2012) and African American gay men living with HIV (Hergenrather et al., 2013). To our knowledge, there is only one study that has examined the lived experience of hope in university students, centered on prospective teachers and their hopes for their teaching careers. The results indicated hope oriented around an active/passive axis, providing support for some of the goal-oriented cognitive components present in Snyder's model, as well as a generalized positive expectation that is more representative of the construct of optimism (Eren and Yeşilbursa, 2017). Participants also reported that both internal and external sources, such as peers, family, and friends, contributed to the experience of hope, providing further support for the need to incorporate an interpersonal dimension. These results demonstrate how qualitative studies can complement and enrich an understanding of the lived experience of hope and how it impacts adaptive outcomes, such as teacher retention.

Studies of hope in recent years suggest a shift to more mixedmethods and qualitative designs (see Figure 3). However, this still represents a very small proportion of studies (approximately $10 \%$ in this review) consistent with trends reported in the broader positive psychology literature (Donaldson et al., 2015). This trend is to be expected in a field that initially embraced a perspective of positivism that views qualitative research as less valuable and scientific (Mruk, 2006). Even when scholars aim to bring more methodological pluralism to their research, they have been thwarted by the dominant narrative of what constitutes scientific knowledge. For example, Shane Lopez, one of the leading scholars in hope research, reported being asked to reduce the qualitative aspects of a mixed-methods paper he submitted to a top positive psychology journal (personal communication, cited in Friedman, 2008).

Expanding methodologies to include more qualitative components can facilitate inquiry into some of the underresearched areas of investigation in hope theory, such as enabling a deepened picture of how hope is experienced and the nature of how it acts as a protective or enabling factor in adaptive functioning. Qualitative methodologies are ideal for this type of research question because they value the messiness and complexity of the human experience in a sociocultural environment, which can build upon our existing knowledge base. We are not arguing that they are a better approach, but rather that developing methodological diversity increases 


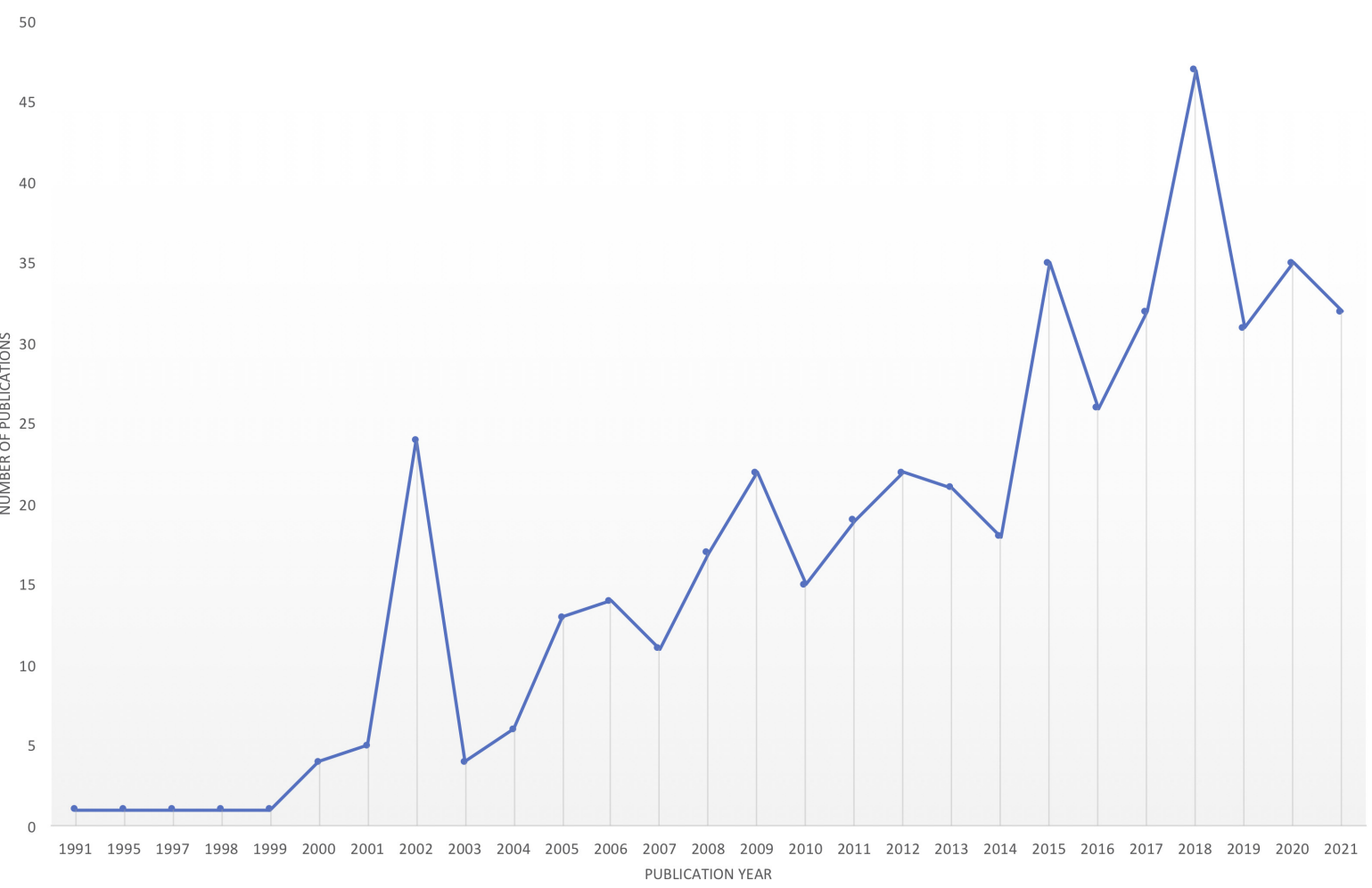

FIGURE 3 | Analysis of the type of research method (quantitative, mixed-methods, qualitative) utilized by year.

knowledge formation (Hefferon et al., 2017). Said another way, qualitative approaches can add color and texture to the lines that have been drawn from the quantitative approaches to date. An interdisciplinary approach that integrates more holistic and inductive methods to examine the emergence of hope can help drive the next level of knowledge in the development of hope theory.

\section{A "NEW HOPE" IN TAKING AN INTEGRATIVE PERSPECTIVE}

Several scholars have argued that consilience, the principle of bringing together evidence from seemingly independent sources to converge in a common groundwork of explanation, is one of the most promising pathways to scientific advancement (Wilson, 1998; Siegel, 2014; Scharmer, 2016). To achieve this requires a move away from the traditional manner of conducting research that leans toward homogenous and disciplinary silos, toward a more heterogeneous and interdisciplinary approach (Rhoten, 2004). Indeed, broadening both our epistemological and methodological horizons can enable us to reveal new and ground-breaking insights. However, it can also present unique challenges in integrating different ways of knowing; an ongoing challenge in interdisciplinary research, which requires mastery of specific competencies to facilitate respectful dialogue to deepen understanding and integrate different epistemological and methodological approaches (Larson et al., 2011).
Law (2016) underscores the importance of reflective practice in this endeavor, suggesting we "re-search" to integrate different perspectives. Re-searching refers to the practices of engaging in a reflective process throughout the entire life-cycle of research; from ongoing questioning about the assumptions that underpin our research design and selection of methods, through to self-questioning our assumptions and sociocultural context that influences our selection and interpretation of data (Law, 2016). Methodologies that acknowledge the cocreative process of knowledge-making with participants are also essential to achieve this aim (Alcoff, 1991). Unfortunately, methods rooted in positivist epistemologies typically assume the researcher possesses greater interpretative and analytical expertise and knowledge than the research participants (Kleinsasser, 2000).

Shotter (1993) also provides a strong argument for this approach in broadening our knowledge development. He positions the importance of "knowing from within" as a third way of knowing, that complements our traditional focus on "knowing that" and "knowing how" in psychological research. Given the lack of diversity in positive psychology research dominated by Western, Industrialized, Educated, Rich, and Democratic (WEIRD) populations (Rao and Donaldson, 2015), this "knowing from within" can give rise to a more nuanced perspective that is representative and validating of different views. Utilizing more inclusive participatory approaches that give voice and empower the participants themselves in developing knowledge can help bridge some of this gap. 
The research agenda we are proposing utilizes a methodology that explicitly facilitates co-creation and participant agency in the research process. Using approaches that enable this, such as Participatory Narrative Inquiry (PNI), can add value in shedding light on participants' meaning and attributions to make sense of the experience of hope (Czarniawska, 2004). The origins of the PNI methodology are in the systems sciences, influenced by the development of Cynefin, a conceptual framework that helps make sense of influences in a complex and complicated environment (Snowden, 2002). PNI is an approach that senses patterns in the social system through the analysis of stories. The participants play a pivotal role in analyzing those stories to understand the system's complexity (Kurtz, 2014). Stories have long been used to help us navigate complex social problems, as words are used as tools for meaning-making and constructing mental models (Shotter, 1993; Gottschall, 2012). The inherent simplexity in using stories is that they are both nouns and verbs and thus can provide both research data and methodology for inquiry.

By involving participants in sharing stories and the sensemaking process of research, we empower them to give voice to their own experiences and play a key role in contributing to knowledge development. It may also be that this method can provide a two-pronged role as both inquiry and intervention. For example, in a participatory narrative inquiry into mental health recovery, participants described the method as giving them hope, providing them with "a ladder" that facilitated autonomy and direction to climb out of the loneliness and isolation of depression and reconnect with society and work (Torrissen and Stickley, 2018).

Narrative has been described as a two-way reflexive process in which language is used as the vehicle to "construct, to organize, and to attribute meaning to our stories" (Anderson, 1997, p. 213). This process enables the storyteller to make sense of their experience through story sharing and invites the researcher into this sense-making process, giving them unique insight into lay theories of how hope emerges and is experienced. The use of narrative methods rather than surveys also allows us to represent and integrate changes and events in our lives into a comprehensive story. We can include causes and consequences of events, plots, subplots, and overarching themes to weave a coherent narrative of our experience (Smyth et al., 2012). The richness of stories as a source of data and methodology for investigating wicked problems lies in their inherent nature, that is, "stories form complex emergent patterns and all complex patterns have stories" (Kurtz, 2014, p. 633).

Participatory Narrative Inquiry is an excellent example of methodological pluralism that integrates various data sources and ways of knowing (Friedman, 2008). For example, data derived from a more positivist epistemology can be integrated, forming part of the material for sense-making. They provide data into one perspective, while data from methodologies rooted in social constructivist epistemologies offer another view, including a gateway into the mental models that drive these perspectives (Kurtz, 2014). The triangulation of data supports the development of a deeper perspective of the subject of inquiry. PNI can also incorporate analytical methods from various disciplines such as systems mapping, natural language processing, and participatory theater. This provides a unique process for integrating knowledge from different disciplinary perspectives and different meta-theoretical philosophies of knowledge.

Complex social problems deserve diverse perspectives to address the multiplicity and interconnectedness of potential causes and contributory factors. We contend that stories may be an under-tapped resource in the use of interdisciplinary research designs to examine the complexity of the human experience in a way that balances the boundaries of time and resources without compromising cohesiveness.

\section{CONCLUSION}

Our manuscript has sought to pave the way forward in the next generation of research in hope theory by outlining a "storyboard" that explores both the backstory of the development of hope theory and a roadmap to uncover some of the as yet untold stories of hope. One of our goals in this critical review of hope theory was to pay homage to the scholarly icons of Rick Snyder and Shane Lopez, whose legacies live on in the impact their work has had across a broad range of disciplines. Their choice to "get straight into the action" has paved the way for a significant number of eminent scholars who have followed in their footsteps and taken up the charge to carry on this vital work, providing us with crucial insights into the merits of hope as a fundamental resource to support thriving.

By analyzing the roots of the development of Snyder's hope theory, we have provided insights into the sociohistorical context that influenced the meta-theoretical assumptions that underpin hope theory. This context helps us understand some of the technical limitations that have impeded the operationalization of hope theory and subsequently led to several gaps in the ensuing research base. Perhaps the most significant of these is the impact of the lost dynamics between elements that facilitate the emergence of hope. Of course, we know the story does not end here, but rather this may provide the necessary "cliffhanger" that creates the impetus and energy for the subsequent development of this story.

We propose that this is best achieved through a dynamic systems reconceptualization of hope as a pathway to addressing these limitations. This research agenda aims to create a new storyline that expands our operationalization of hope to deepen understanding of the dynamic interactions between the elements that create the unique alchemical reaction of hope. This may include introducing two new "characters," namely, WhyPower and WePower, expanding the theoretical horizons of hope to integrate systemic intrapersonal and interpersonal perspectives.

However, to translate this vision to action, it is imperative that we broaden our methodological approaches to facilitate an examination of the complexities and interdependencies in such a model. In the same way that we have seen significant advances in technology since the first episodes of Star Wars that have enhanced the cinematic experience and storytelling, we 
can also draw on more sophisticated interdisciplinary methods now available to advance the study of hope. We advocate a pragmatist approach that pays homage to the wealth of knowledge generated through the methodologies that have dominated the research to date, while intentionally selecting diverse methods to broaden and deepen our understanding of the emergence of hope in young people. Engaging in research covering the full spectrum of epistemological perspectives can enable us to develop richer pictures of positive psychology's fundamental theories and principles; and, in doing so, realize the vision of "a new hope" for the field.

\section{REFERENCES}

Abe, J. A. (2016). A longitudinal follow-up study of happiness and meaningmaking. J. Posit. Psychol. 11, 489-498.

Ahmet, A., and Umran, A. (2014). Authenticity as a predictor on hope in Turkish university students. Educ. Sci. Psychol. 28, 64-70.

Alcoff, L. (1991). The problem of speaking for others. Cult. Critiq. 20, 5-32. doi: $10.2307 / 1354221$

Anderson, H. (1997). Conversation, language, and possibilities: A postmodern approach to therapy. New York, NY: Basic Books.

Bauman, L. V. (2015). The impact of a psychological capital intervention on college student wellbeing. Ph. D. thesis. Azusa: Azusa Pacific University.

Baumsteiger, R., Mangan, S., Bronk, K. C., and Bono, G. (2019). An integrative intervention for cultivating gratitude among adolescents and young adults. J. Posit. Psychol. 14, 807-819. doi: 10.1080/17439760.2019.1579356

Bernardo, A. B. I. (2010). Extending hope theory: Internal and external locus of trait hope. Pers. Individ. Differ. 49, 944-949. doi: 10.1016/j.paid.2010.07.036

Bernardo, A. B. I., and Mendoza, N. B. (2020). Measuring hope during the COVID-19 outbreak in the Philippines: Development and validation of the state locus-of-Hope scale short form in Filipino. Curr. Psycholo. J. Diverse Perspect. Diverse Psychol. Iss. 1:887-x. doi: 10.1007/s12144-020-00887-x

Bernardo, A. B. I., Yeung, S. S., Resurreccion, K. F., Resurreccion, R. R., and Khan, A. (2018). External locus-of-hope, well-being, and coping of students: A cross-cultural examination within Asia. Psychol. Schools 55, 908-923.

Bronfenbrenner, U. (1979). The ecology of human development: Experiments by nature and design. Cambridge, MA: Harvard University Press.

Bronk, K. C. (2013). Purpose in life: A critical component of optimal youth development. Berlin: Springer Science \& Business Media.

Buetow, S. (2007). Health research methods: A tabular presentation. New York, NY: Nova Science Pub Incorporated.

Buyukgoze-Kavas, A. (2016). Predicting career adaptability from positive psychological traits. Career Dev. Quart. 64, 114-125. doi: 10.1002/cdq.12045

Callina, K. S., Snow, N., and Murray, E. D. (2018). “The history of philosophical and psychological perspectives on hope: Toward defining hope for the science of positive human development," in The Oxford Handbook of Hope, eds M. W. Gallagher and S. J. Lopez (Oxford: Oxford Handbooks).

Chang, E. C. (1998). Hope, problem-solving ability, and coping in a college population: Some implications for theory and practice. J. Clin. Psychol. 54, 953962. doi: 10.1002/(sici)1097-4679(199811)54:7\&lt;953::aid-jclp9\&gt;3.0.co;2-f

Chang, E. C., and Banks, K. H. (2007). The color and texture of hope: Some preliminary findings and implications for hope theory and counseling among diverse racial/ethnic groups. Cult. Divers. Ethnic Minority Psychol. 13, 94-103. doi: 10.1037/10999809.13.2.94

Chang, E. C., and DeSimone, S. L. (2001). The influence of hope on appraisals, coping, and dysphoria: A test of hope theory. J. Soc. Clin. Psychol. 20, 117-129. doi: 10.1521 /jscp.20.2.117.22262

Chang, E. C., Chang, O. D., Li, M., Xi, Z., Liu, Y., Zhang, X., et al. (2019). Positive emotions, hope, and life satisfaction in Chinese adults: A test of the broadenand-build model in accounting for subjective well-being in Chinese college students. J. Posit. Psychol. 14, 829-835. doi: 10.1080/17439760.2019.1579358

Cheavens, J. S., Heiy, J. E., Feldman, D. B., Benitez, C., and Rand, K. L. (2019). Hope, goals, and pathways: Further validating the hope scale with observer ratings. J. Posit. Psychol. 14, 452-462. doi: 10.1080/17439760.2018.1484937

\section{AUTHOR CONTRIBUTIONS}

$\mathrm{RC}$ conceptualized the research questions for this review and theoretical expansion of Snyder's theory, developed the search protocols, conducted the research using PRISMA-Sc, developed and organized the database, including coding $80 \%$ of the data, and wrote the manuscript. PW and LO added contextual insights and provided contributions in shaping arguments. JC-M coded studies by discipline and performed the mapping analysis. PW and RC contributed to the manuscript revision, read, and approved the submitted version.

Cole, B. P., Baglieri, M., Ploharz, S., Brennan, M., Ternes, M., Patterson, T., et al. (2019). What's right with men? Gender role socialization and men's positive functioning. Am. J. Men's Health 13:1557988318806074. doi: 10.1177/ 1557988318806074

Collins, H. (2010). Creative research: The theory and practice of research for the creative industries. West Sussex: AVA Publishing.

Collins, K. M. T., Onwuegbuzie, A. J., and Jiao, Q. G. (2009). Hope as a predictor of performance of graduate-level cooperative groups in research methodology courses. Int. J. Teaching Learn. Higher Educ. 21, 148-157.

Crain, M., and Koehn, C. (2012). The essence of hope in domestic violence support work: A hermeneutic-phenomenological inquiry. J. Mental Health Counsel. 34, 170-188. doi: 10.17744/mehc.34.2.am6j432352416nh8

Crane, M. F. (2014). The differential impact of agency and pathway thinking on goal pursuit and university exam performance. Pers. Individ. Differ. 58, 20-25. doi: 10.1016/j.paid.2013.09.026

Czarniawska, B. (2004). Narratives in social science research. London: Sage Publications.

Damon, W., and Malin, H. (2020). "The development of purpose," in The Oxford handbook of moral development: An interdisciplinary perspective, ed. L. A. Jensen (Oxford: Oxford handbooks online).

Damon, W., Menon, J., and Bronk, K. C. (2003). The development of purpose during adolescence. Appl. Dev. Sci. 7, 119-128.

Davidson, C. L., and Wingate, L. R. (2011). Racial disparities in risk and protective factors for suicide. J. Black Psychol. 37, 499-516.

Davidson, O. B., Feldman, D. B., and Margalit, M. (2012). A focused intervention for $1^{\text {st }}$ year college students: Promoting hope, sense of coherence, and self-efficacy. J. Psychol. 146, 333-353. doi: 10.1080/00223980.2011. 634862

Delle Fave, A., Brdar, I., Freire, T., Vella-Brodrick, D., and Wissing, M. P. (2011). The eudaimonic and hedonic components of happiness: Qualitative and quantitative findings. Soc. Indicat. Res. 100, 185-207.

Denovan, A., and Macaskill, A. (2013). An interpretative phenomenological analysis of stress and coping in first year undergraduates. Br. Educ. Res. J. 39, 1002-1024.

Dixson, D. D. (2019). Hope into action: How clusters of hope relate to successoriented behavior in school. Psychol. Schools 56, 1493-1511. doi: 10.1002/pits. 22299

Dixson, D. D., Keltner, D., Worrell, F. C., and Mello, Z. (2017). The magic of hope: Hope mediates the relationship between socioeconomic status and academic achievement. J. Educ. Res. 2017:1302915. doi: 10.1080/00220671.2017.1302915

Donaldson, S. I., Dollwet, M., and Rao, M. A. (2015). Happiness, excellence and optimal functioning revisited: Examining the peer-reviewed literature linked to positive psychology. J. Posit. Psychol. 10, 185-195. doi: 10.1080/17439760.2014. 943801

Du, H., and King, R. B. (2013). Placing hope in self and others: Exploring the relationships among self-construals, locus of hope, and adjustment. Pers. Individ. Differ. 54, 332-337. doi: 10.1016/j.paid.2012.09.015

Eren, A. (2015). 'Not only satisfied and responsible, but also hopeful': Prospective teachers' career choice satisfaction, hope, and personal responsibility. Cambridge J. Educ. 45, 149-166. doi: 10.1080/0305764X.2014.930417

Eren, A., and Yeşilbursa, A. (2017). A qualitative investigation of prospective teachers' hopes, their sources, and motivational forces. Irish Educ. Stud. 36, 253-271. doi: 10.1080/03323315.2017.1327362 
Feldman, D. B., and Dreher, D. E. (2012). Can hope be changed in 90 minutes? Testing the efficacy of a single-session goal-pursuit intervention for college students. J. Happ. Stud. 13, 745-759. doi: 10.1007/s10902-011-9292-4

Feldman, D. B., and Kubota, M. (2015). Hope, self-efficacy, optimism, and academic achievement: Distinguishing constructs and levels of specificity in predicting college grade-point average. Learn. Individ. Differ. 37, 210-216. doi: 10.1016/j.lindif.2014.11.022

Feldman, D. B., and Snyder, C. R. (2005). Hope and the meaningful life: Theoretical and empirical associations between goal-directed thinking and life meaning. J. Soc. Clin. Psychol. 24, 401-421.

Feldman, D. B., Davidson, O. B., and Margalit, M. (2015). Personal resources, hope, and achievement among college students: The conservation of resources perspective. J. Happ. Stud. 16, 543-560. doi: 10.1007/s10902-014-9508-5

Feldman, D. B., Rand, K. L., and Kahle-Wrobleski, K. (2009). Hope and goal attainment: Testing a basic prediction of hope theory. J. Soc. Clin. Psychol. 28, 479-497. doi: 10.1521/jscp.2009.28.4.479

Feldman, D., Balaraman, M., and Anderson, C. (2018). "Hope and Meaningin-Life: Points of Contact Between Hope Theory and Existentialism," in The Oxford Handbook of Hope, eds M. W. Gallagher and S. J. Lopez (Oxford: Oxfordhandbooks).

Flood, R. L. (2010). The relationship of 'systems thinking' to action research. Syst. Pract. Action Res. 23, 269-284. doi: 10.1007/s11213-010-9169-1

Friedman, H. (2003). Methodolotry and graphicacy. Am. Psychol. 58, 817-818.

Friedman, H. (2008). Humanistic and positive psychology: The methodological and epistemological divide. Humanist. Psychol. 2:113.

Gallagher, M. W., and Lopez, S. J. (2009). Positive expectancies and mental health: Identifying the unique contributions of hope and optimism. J. Posit. Psychol. 4:548556.

Gallagher, M. W., Marques, S. C., and Lopez, S. J. (2017). Hope and the academic trajectory of college students. J. Happ. Stud. 18, 341-352.

Gallup (2009). Hope as an outcome of strengths development in freshmen in high school. Omaha, NE: Unpublished raw data.

Gallup (2018). Gallup student poll USA Overall Public Fall. Avaiable online at: http://www.pathwaystoadultsuccess.org/wp-content/uploads/2020/05/GSP_ Scorecard_Overall_US_Public_Fall_2018.pdf

Gallup (2021). Australian Gallup student poll: National cohort term 1, 2020. Avaiable online at: https://www.gallup.com/services/336176/2020-gallupstudent-poll-australia-new-zealandreport

Gergen, K. J. (1990). Toward a postmodern psychology. Humanist. Psychol. 18, 23-34.

Goldman, A., and O'Connor, C. (2021). "Social epistemology," in The Stanford Encyclopedia of Philosophy, ed. E. N. Zalta (Stanford: Stanford University Press).

Goodman, F. R., Disabato, D. J., Kashdan, T. B., and Machell, K. A. (2017). Personality strengths as resilience: A one-year multiwave study. J. Pers. 85, 423-434. doi: 10.1111/jopy.12250

Gottschall, J. (2012). The storytelling animal: How stories make us human. Boston: Houghton Mifflin Harcourt.

Griggs, S., and Crawford, S. L. (2017). Hope, core self-evaluations, emotional wellbeing, health-risk behaviors, and academic performance in university freshmen. J. Psychosoc. Nurs. Mental Health Serv. 55, 33-42. doi: 10.3928/0279369520170818-11

Harris, C. M. (2015). Hope for success: Effects of an academic intervention for at-risk college students. Ph. D. thesis. Alabama: The University of Alabama.

Hefferon, K., Ashfield, A., Waters, L., and Synard, J. (2017). Understanding optimal human functioning - The 'call for qual' in exploring human flourishing and wellbeing. J. Posit. Psychol. 12, 211-219. doi: 10.1080/17439760.2016. 1225120

Hergenrather, K. C., Geishecker, S., Clark, G., and Rhodes, S. D. (2013). A Pilot Test of the HOPE Intervention to Explore Employment and Mental Health Among African American Gay Men Living With HIV/AIDS: Results From a CBPR Study. AIDS Educ. Prevent. 5:405422. doi: 10.1521/aeap.2013.25.5.405

Hobfoll, S. E. (2002). Social and psychological resources and adaptation. Rev. General Psychol. 6, 307-324. doi: 10.1037/a0030803

Kelly, J. G. (1966). Ecological constraints on mental health services. Am. Psychol. 21, 535-539. doi: 10.1037/h0023598

Kemp, A. H., and Quintana, D. S. (2013). The relationship between mental and physical health: insights from the study of heart rate variability. Int. J. Psychophysiol. 89, 288-296. doi: 10.1016/j.ijpsycho.2013.06.018
Kern, M. L., Williams, P., Spong, C., Colla, R., Sharma, K., Downie, A., et al. (2020). Systems informed positive psychology. J. Posit. Psychol. 15, 705-715. doi: $10.1080 / 17439760.2019 .1639799$

Keyes, C. L. M. (2006). Subjective wellbeing in mental health and human development research worldwide: An introduction. Soc. Indicat. Res. 77, 1-10.

Keyes, C. L. M. (2011). Authentic purpose: The spiritual infrastructure of life. J. Manage. Spiritual. Rel. 8, 281-297.

Kleinsasser, A. M. (2000). Researchers, reflexivity, and good data: Writing to unlearn. Theory Into Pract. 39, 155-162. doi: 10.1207/s15430421tip3903_6

Kurtz, C. (2014). Working with stories in your community or organization: Participatory narrative inquiry, 3rd Edn. Los Angeles, CA: Kurtz-Fernhout Publishing.

Larson, E. L., Landers, T. F., and Begg, M. D. (2011). Building interdisciplinary research models: A didactic course to prepare interdisciplinary scholars and faculty. Clin. Translat. Sci. 4, 38-41. doi: 10.1111/j.1752-8062.2010.00258.x

Law, S. F. (2016). Unknowing researcher's vulnerability: Re-searching inequality on an uneven playing field. J. Soc. Politic. Psychol. 4, 521-536. doi: 10.5964/jspp. v4i2.439

Lee, J. Y., and Gallagher, M. W. (2018). "Hope and wellbeing," in The Oxford Handbook of Hope, eds M. W. Gallagher and S. J. Lopez (Oxford: Oxfordhandbooks).

Liu, S. R., Kia-Keating, M., and Modir, S. (2017). Hope and adjustment to college in the context of collective trauma. J. Am. College Health 65, 323-330. doi: 10.1080/07448481.2017.1312412

Lomas, T., Hefferon, K., and Ivtzan, I. (2015). The LIFE model: A meta-theoretical conceptual map for applied positive psychology. J. Happ. Stud. 16, 1347-1364.

Lomas, T., Waters, L., Williams, P., Oades, L. G., and Kern, M. L. (2020). Third wave positive psychology: broadening towards complexity. J. Posit. Psychol. 2020:1805501. doi: 10.1080/17439760.2020.1805501

Lopez, S. J. (2010). Making ripples: How principals and teachers can spread hope throughout our schools. Phi Delta Kappan 92, 40-44.

Lopez, S. J., Snyder, C. R., and Pedrotti, J. T. (2003). "Hope: Many definitions, many measures," in Positive psychological assessment: A handbook of models and measures, eds S. J. Lopez and C. R. Snyder (Washington, DC: American Psychological Association), 91-106.

Lucas, A. B., Chang, E. C., Li, M., Chang, O. D., Yu, E. Y., and Hirsch, J. K. (2020). Trauma and suicide risk in college students: Does lack of agency, lack of pathways, or both add to further risk? Soc. Work 65, 105-113. doi: 10.1093/sw/ swaa007

Luo, Y.-F., Yang, S.-C., Gong, R., and Lu, C.-M. (2019). Learning performance of university students from the perspective of positive psychology. Soc. Behav. Personal. 47:7595. doi: 10.2224/sbp.7595

Macaskill, A., and Denovan, A. (2013). Developing autonomous learning in first year university students using perspectives from positive psychology. Stud. Higher Educ. 38:124142. doi: 10.1080/03075079.2011.56 6325

Magaletta, P. R., and Oliver, J. M. (1999). The hope construct, will, and ways: Their relations with self-efficacy, optimism, and general wellbeing. J. Clin. Psychol. 55, 539-551. doi: 10.1002/(sici) 1097-4679(199905)55:5\&lt;539::aid-jclp2\&gt;3. $0 . \mathrm{co} ; 2-\mathrm{g}$

Mascaro, N., and Rosen, D. H. (2005). Existential meaning's role in the enhancement of hope and prevention of depressive symptoms. J. Pers. 73, 985-1013. doi: 10.1111/j.1467-6494.2005.00336.x

McKnight, P. E., and Kashdan, T. B. (2009). Purpose in life as a system that creates and sustains health and wellbeing: An integrative, testable theory. Rev. General Psychol. 13, 242-251.

Mead, J., Fisher, Z., and Kemp, A. H. (2021). Moving beyond disciplinary silos towards a transdisciplinary model of wellbeing: An invited review. Front. Psychol. 12:642093. doi: 10.3389/fpsyg.2021.642093

Mruk, C. (2006). Self-esteem research, theory, and practice: Toward a positive psychology of selfesteem, 3rd Edn. Berlin: Springer.

Muwonge, C. M., Schiefele, U., Ssenyonga, J., and Kibedi, H. (2017). Determinants of persistence among science teacher-trainees: Examining the role of selfefficacy, task value, and academic hope. J. Sci. Teacher Educ. 28, 522-548. doi: 10.1080/1046560X.2017.1379860

Onwuegbuzie, A. J., and Snyder, C. R. (2000). Relations between hope and graduate students' coping strategies for studying and examination-taking. Psychol. Rep. 86, 803-806. doi: $10.2466 /$ pro.2000.86.3.803 
Pan, Y., Yang, Z., Han, X., and Qi, S. (2021). Family functioning and mental health among secondary vocational students during the COVID-19 epidemic: A moderated mediation model. Pers. Individ. Differ. 171:110490. doi: 10.1016/j. paid.2020.110490

Papantoniou, G., Moraitou, D., Katsadima, E., and Dinou, M. (2010). Action control and dispositional hope: An examination of their effect on self-regulated learning. Electr. J. Res. Educ. Psychol. 8, 5-32.

Peters, G. B. (2017). What is so wicked about wicked problems? A conceptual analysis and research program. Pol. Soc. 36, 385-396.

Phillips, S. L. (2011). Path models of vocational calling in Christian college students. Christian Higher Educ. 10, 296-323. doi: 10.1080/15363759.2011.576220

Rao, M. A., and Donaldson, S. I. (2015). Expanding opportunities for diversity in positive psychology: An examination of gender, race, and ethnicity. Can. Psychol. 3:271. doi: 10.1037/cap0000036

Reker, G. T., and Wong, P. T. P. (1988). "Aging as an individual process: Toward a theory of individual meaning," in Emergent theories of aging, eds J. E. Birren and V. I. Bengston (New York, NY: Springer), 214-246.

Rhoten, D. (2004). Interdisciplinary research: Trend or transition. Items Iss. 5, 6-11.

Robinson, C., and Rose, S. (2010). Predictive, construct, and convergent validity of general and domain-specific measures of hope for college student academic achievement. Res. Schools 17, 38-52.

Roffey, S. (2015). Becoming an agent of change for school and student wellbeing. Educ. Child Psychol. 32, 21-30. doi: 10.3928/01484834-20170323-12

Ryff, C. D. (1989). Happiness is everything, or is it? Explorations on the meaning of psychological well-being. J. Pers. Soc. Psychol. 57, 1069-1081. doi: 10.1037/ 0022-3514.57.6.1069

Savage, J. S., and Smith, A. B. (2007). General and specific goal orientations as correlates of adult student degree completion: Lessons from the community college of the Air Force. J. College Stud. Retent. 9, 461-485. doi: 10.2190/CS.9.4.d

Scharmer, O. (2016). Theory U: Leading from the future as it emerges, 2 nd Edn. Oakland, CA: Berrett-Koehler Publishers.

Shotter, J. (1993). Cultural politics of everyday life: Social constructionism, rhetoric and knowing of the third kind. Berkshire: Open University Press.

Siegel, D. (2014). Brainstorm: The power of the adolescent brain. London, UK: Penguin.

Smyth, J. M., Pennebaker, J. W., and Arigo, D. (2012). What are the health effects of disclosure? Handb. Health Psychol. 2012, 175-191.

Snowden, D. (2002). Complex acts of knowing: Paradox and descriptive self-awareness. J. Knowl. Manage. 6, 100-111. doi: 10.1108/13673270210 424639

Snyder, C. R. (1989). Reality negotiation: From excuses to hope and beyond. J. Soc. Clin. Psychol. 8, 130-157. doi: 10.1521/jscp.1989.8.2.130

Snyder, C. R. (1995). Conceptualizing, measuring, and nurturing hope. J. Counsel. Dev. 73, 355-360. doi: 10.1002/j.1556-6676.1995.tb0 1764.x

Snyder, C. R. (2002). Hope theory: Rainbows in the mind. Psychol. Inquiry 13, 249-275. doi: 10.1207/s15327965pli1304_01

Snyder, C. R., Cheavens, J., and Michael, S. T. (1999). "Hoping," in Coping: The psychology of what works, ed. C. R. Snyder (Oxford: Oxford University Press), 205-231.

Snyder, C. R., Harris, C., Anderson, J. R., Holleran, S. A., Irving, L. M., Sigmon, S. T., et al. (1991). The will and the ways: Development and validation of an individual-differences measure of hope. J. Pers. Soc. Psychol. 60, 570-585. doi: $10.1037 / / 0022-3514.60 .4 .570$

Snyder, C. R., Hoza, B., Pelham, W. E., Rapoff, M. A., Ware, L., Danovsky, M., et al. (1997). The Development and Validation of the Children's Hope Scale. J. Pediatr. Psychol. 22, 399-421. doi: 10.1093/jpepsy/22.3.399
Snyder, C. R., Shorey, H. S., Cheavens, J., Pulvers, K. M., Adams, V. H. III., and Wiklund, C. (2002). Hope and academic success in college. J. Educ. Psychol. 94, 820-826. doi: 10.1037/0022-0663.94.4.820

Snyder, C. R., Sympson, S. C., Ybasco, F. C., Borders, T. F., Babyak, M. A., and Higgins, R. L. (1996). Development and validation of the State Hope Scale. J. Pers. Soc. Psychol. 70, 321-335.

Soria, K., and Stubblefield, R. (2015). Building strengths awareness and hope in students' transition to higher education. College Stud. Affairs J. 33, 47-65. doi: $10.1353 / \mathrm{csj} .2015 .0007$

Steger, M. F. (2018a). "Meaning in life: A unified model," in The Oxford handbook of positive psychology, 3rd Edn, eds C. R. Snyder, S. J. Lopez, L. M. Edwards, and S. J. Marques (Oxford: Oxford handbooks online). doi: 10.1007/978-94-0076527-6_4

Steger, M. F. (2018b). "Meaning and wellbeing," in Handbook of wellbeing, eds E. Diener, S. Oishi, and L. Tay (Salt Lake City, UT: DEF Publishers).

Steptoe, A., Deaton, A., and Stone, A. A. (2015). Subjective wellbeing, health, and ageing. Lancet 385, 640-648. doi: 10.1016/s0140-6736(13)61489-0

Tennen, H., Affleck, G., and Tennen, R. R. (2002). The theory and measurement of hope. Psychol. Inquiry 13, 311-317.

Torrissen, W., and Stickley, T. (2018). Participatory theatre and mental health recovery: A narrative inquiry. Perspect. Public Health 138, 47-54. doi: 10.1177/ 1757913917723944

Vela, J. C., Smith, W. D., Whittenberg, J. F., Guardiola, R., and Savage, M. (2018). Positive psychology factors as predictors of Latina/o college students' psychological grit. J. Multicult. Counsel. Dev. 46, 2-19. doi: 10.1002/jmcd. 12089

Viner, R. M., Ozer, E. M., Denny, S., Marmot, M., Resnick, M., Fatusi, A., et al. (2012). Adolescence and the social determinants of health. Lancet 379, 16411652.

Wandeler, C. A., and Bundick, M. J. (2011). Hope and self-determination of young adults in the workplace. J. Posit. Psychol. 6, 341-354. doi: 10.1080/17439760. 2011.584547

Ward, K., Hoare, K. J., and Gott, M. (2015). Evolving from a positivist to constructionist epistemology while using grounded theory: Reflections of a novice researcher. J. Res. Nurs. 20, 449-462. doi: 10.1177/1744987115597731

Weis, R., and Speridakos, E. C. (2011). A meta-analysis of hope enhancement strategies in clinical and community settings. Psychol. Well Being 1, 1-16.

Williams, P., Kern, M. L., and Waters, L. (2016). Inside-out-outside-in: A dual approach process model to developing work happiness. Int. J. Wellbeing 6, 30-56. doi: 10.5502/ijw.v6i2.489

Wilson, E. O. (1998). Consilience: The unity of science. New York, NY: Knopf.

Conflict of Interest: The authors declare that the research was conducted in the absence of any commercial or financial relationships that could be construed as a potential conflict of interest.

Publisher's Note: All claims expressed in this article are solely those of the authors and do not necessarily represent those of their affiliated organizations, or those of the publisher, the editors and the reviewers. Any product that may be evaluated in this article, or claim that may be made by its manufacturer, is not guaranteed or endorsed by the publisher.

Copyright (c) 2022 Colla, Williams, Oades and Camacho-Morles. This is an openaccess article distributed under the terms of the Creative Commons Attribution License (CC BY). The use, distribution or reproduction in other forums is permitted, provided the original author(s) and the copyright owner(s) are credited and that the original publication in this journal is cited, in accordance with accepted academic practice. No use, distribution or reproduction is permitted which does not comply with these terms. 